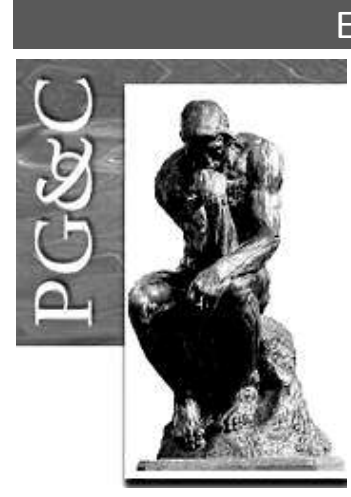

\title{
CINCO ANOS DO LANÇAMENTO DO SPELL - SCIENTIFIC PERIODICALS ELECTRONIC LIBRARY E DA INDEXAÇÃO DA REVISTA PERSPECTIVAS EM GESTÃO \& CONHECIMENTO NESTE PORTAL
}

O Spell - Scientific Periodicals Electronic Library ${ }^{1}$ é um portal brasileiro que envolve um sistema de indexação, pesquisa e disponibilização gratuita da produção científico-profissional nas áreas de Administração, Contabilidade e Turismo. Com o objetivo central de promover o acesso, organização, disseminação e análise da produção científica, o Spell cumpre com uma dupla missão: organizar, numa única base de dados, um significativo acervo de conhecimento e proporcionar acesso livre a usuários interessados na produção científico-profissional.

Este portal foi lançado em 2012, concentrando, inicialmente, a produção científica das áreas de Administração, Contabilidade e Turismo publicadas a partir de 2008. Por esta razão, contemplando iniciativas nacionais exitosas de editoração de revistas de alta qualidade, desde o seu lançamento o Spell convidou a revista Perspectivas em Gestão \& Conhecimento - PG\&C para fazer parte do seu projeto inovador, tendo a produção completa da nossa revista desde o ano de 2011 armazenada, quando da sua fundação, valorizando a produção da PG\&C em diálogos multi, inter, pluri e transdisciplinares dedicados à intercessão e promoção dos diversos saberes sobre Gestão e Conhecimento, abrangendo seus conteúdos advindos das áreas de Administração, Contabilidade e Turismo, em ampliação, por exemplo, das Ciências da Informação, Biblioteconomia, Arquivologia, Comunicação Social, Computação, Ciências Sociais, Engenharias, Filosofia, dentre outras. Um leque tão necessário e precioso de saberes que só uma revista como a PG\&C, que nasceu para tal dedicação, e um portal como o Spell, com muita sensibilidade e árduo trabalho, apostariam neste objetivo de acesso, organização, disseminação e análise do que é produzido em nossa revista.

Este Editorial, portanto, é uma homenagem da PG\&C ao portal Spell, que tanto vem ajudando a divulgação do conhecimento científico no Brasil nestes seus cinco anos de existência, como uma iniciativa com o apoio irrestrito da Associação Nacional de Pesquisa e Pós-Graduação em Administração - ANPAD².

Nesta jornada colaborativa entre a PG\&C e o Spell, anunciamos que, a partir deste volume 7, número 1 de 2017 da revista, o Spell vem nos proporcionar a geração e utilização do Digital Object Identifier (DOI), um padrão internacional para identificação de documentos em redes de computadores como a internet. Mais um passo para afirmação da consolidação internacional da PG\&C, o que agradecemos ao portal Spell. Neste sentido, a partir deste número da revista, todos os seus Artigos

\footnotetext{
${ }^{1}$ Ver: http://www.spell.org.br/.

${ }^{2}$ Conforme Resolução da ANPAD no 003 de 17 de junho de 2016, onde aprova normas de gestão e governança do portal eletrônico Spell - Scientific Periodical Electronic Library e dá outras providências. Ver: http://www.spell.org.br/uploads/inclusao-de-periodicos/Spell Governanca Final.pdf.
}

Perspectivas em Gestão \& Conhecimento, João Pessoa, v. 7, n. 1, p. 1-4, jan./jun. 2017. DOI: http://dx.doi.org/10.21714/2236-417X2017v7n1p1

http://periodicos.ufpb.br/ojs2/index.php/pgc. ISSN: 2236-417X. Publicação sob Licença (cc) EY-NC-ND. 
possuirão um número $\mathrm{DOI}$, com fins à facilitação da sua recuperação internacional via internet.

Feita a devida homenagem pela PG\&C, trazemos aos leitores neste número da revista um Artigo de Revisão, 11 Artigos Relatos de Pesquisa, além deste Editorial e do nosso Expediente, onde, neste último item, podem ser encontradas as informações gerais da revista, bem como a relação qualificada dos autores e avaliadores envolvidos neste número.

Como único Artigo de Revisão, de autoria de Danielli Santos Silva e Regina Célia Belluzzo, temos o artigo intitulado GESTÃO DO CONHECIMENTO E SABER NAS BIBLIOTECAS UNIVERSITÁRIAS: REFLEXÕES DE IMPORTÂNCIA NA CONTEMPORANEIDADE, onde é apresentada a revisão da literatura especializada acerca da gestão do conhecimento e do saber nas Bibliotecas Universitárias, possibilitando reflexões sobre a importância dessas instituições na contemporaneidade, uma vez que essa área de gestão pode ser considerada um dos principais elementos da economia na atualidade.

Abrindo a seção de 11 Artigos Relatos de Pesquisa, o primeiro artigo, de autoria de

Tatiana Cristina Siqueira Santos, Dorzeli Salete Trzeciak e Gregório Varvakis, intitulado NARRATIVA NO FLUXO DE INFORMAÇÃO PARA O COMPARTILHAMENTO DE CONHECIMENTO EM MPES: PROPOSTA DE UM MODELO, é apresentado um modelo para descrever a narrativa no fluxo de informação para o compartilhamento de conhecimento, em micro e pequenas empresas, sendo uma pesquisa aplicada, com abordagem qualitativa, descritiva que utiliza a pesquisa bibliográfica como procedimento técnico para a sua realização.

O segundo Relato de Pesquisa, intitulado O PAPEL DA EMPRESA JR NO DESENVOLVIMENTO DE COMPETÊNCIAS DE SEUS INTEGRANTES: UM ESTUDO COM EXMEMBROS DA EMAD JR, de autoria de Nicoline Pinheiro Fernandes e Francielle Molon da Silva, tem como objetivo é analisar como o desenvolvimento das competências identificadas na avaliação de desempenho da Emad Jr. é percebido pelos ex-membros dessa organização, identificando as competências que eles consideram ter sido desenvolvidas por participarem da empresa júnior, comparando as competências desenvolvidas nos ex-membros com as projetadas pela avaliação de desempenho da Emad Jr., e identificando como os mesmos que estão exercendo atividade profissional acreditam que as competências adquiridas na empresa júnior contribuíram para o seu crescimento no ambiente de trabalho.

O terceiro Relato de Pesquisa, de autoria de Cicero Aparecido Bezerra e André José Ribeiro Guimarães, intitulado O DESEMPENHO INOVADOR DE AGÊNCIAS DE PUBLICIDADE E SUA RELAÇÃO COM A GESTÃO DO CONHECIMENTO E CONDIÇÕES ORGANIZACIONAIS DE INOVATIVIDADE E CRIATIVIDADE, objetiva identificar a existência de associações entre as condições habilitadoras da inovação, os aspectos capacitadores da gestão do conhecimento, as condições ambientais para a criatividade organizacional e o desempenho inovador das empresas de publicidade.

O quarto Relato de Pesquisa, intitulado O COMÉRCIO ELETRÔNICO (ECOMMERCE): UM ESTUDO COM CONSUMIDORES, de autoria de Marta Cleia Andrade e Naiara Gonçalves Silva, objetiva identificar o posicionamento e a experiência de compra de alguns consumidores do Vale do São Patrício, em relação ao Comércio

Perspectivas em Gestão \& Conhecimento, João Pessoa, v. 7, n. 1, p. 1-4, jan./jun. 2017. 
Eletrônico, em uma região localizada no estado de Goiás. Para isso, foram aplicados questionários com perguntas abertas e fechadas, nas cidades de Rubiataba e Nova América, apontando resultados sobre as principais experiências e opiniões dos consumidores em relação às compras on-line.

O quinto Relato de Pesquisa, de autoria de Luiz Antonio Lourencetti, Mário Sacomano Neto e Gilberto Miller Devós Ganga, intitulado IDENTIFICAÇÃO DE VALORES RELATIVOS AO TRABALHO DE ALUNOS DE PÓS-GRADUAÇÃO, objetiva identificar os valores relativos ao trabalho de alunos de cursos de pós-graduação de uma universidade pública, explorando as diferenças desses valores com variáveis de gênero e tipo de organização em que esses alunos atuam.

O sexto Relato de Pesquisa, de autoria de Antonio lacono e Marcelo Seido Nagano, intitulado PROCESSOS DE APRENDIZAGEM PARA A ACUMULAÇÃO DE CAPACIDADE TECNOLÓGICA: UM ESTUDO EM EMPRESAS DO SETOR DE BENS DE CAPITAL NO BRASIL, tem por objetivo analisar os processos e mecanismos de aprendizagem para a acumulação de competências tecnológicas em empresas. Para alcançar teste objetivo, realizou-se um estudo exploratório, de abordagem qualitativa com 44 empresas do setor de bens de capital mecânico no Brasil.

O sétimo Relato de Pesquisa, intitulado ANÁLISE DAS RELAÇÕES INTERPESSOAIS EM UM JOGO DE EMPRESAS: COMBINANDO SOCIOMETRIA E MÉTODOS ATIVOS EM ADMINISTRAÇÃO, de autoria de Bruno Koenigkan Lopes, Leticia Duarte Andrade, Sheila Serafim da Silva e Murilo Alvarenga Oliveira, tem como objetivo analisar a dinâmica das relações interpessoais e intergrupais em um ambiente laboratorial. Trata-se aqui de um ambiente que simula o processo de tomada de decisão de gestores por meio da técnica jogo de empresas, fundamentada na aprendizagem vivencial - aprender fazendo.

O oitavo Relato de Pesquisa, de autoria de Suzana de Lucena Lira, Wagner Junqueira de Araújo e Emeide Nóbrega Duarte, intitulado CENÁRIOS PROSPECTIVOS PARA IMPLANTAÇÃO DE COMUNIDADES DE PRÁTICA EM UNIDADES DE CONTABILIDADE EM UNIVERSIDADES PÚBLICAS, tem como objetivo desenvolver a informação estratégica por meio da construção de cenários prospectivos para proposição de uma comunidade de prática (CoP) na área contábil de universidades públicas, como ferramenta para auxiliar na gestão do conhecimento.

O nono Relato de Pesquisa, intitulado SISTEMAS DE INFORMAÇÕES PARA GERENCIAMENTO DE RISCOS CORPORATIVOS EM CONTROLADORIA: UM ESTUDO BIBLIOMÉTRICO, de autoria de Eduardo Vieira do Prado, Valeria Rueda Elias Spers, Clovis Luis Padoveze, Andre Luis Bertassi e Luiz Gustavo Camarano Nazareth, tem como objetivo geral mapear as pesquisas sobre o papel da Controladoria na estruturação de sistemas de informação para Gerenciamento de Riscos Corporativos.

O décimo Relato de Pesquisa, de autoria de Ariane Santos, Eduardo Roque Mangini, André Torres Urdan e Fernando Henrique Brasil Rossini, intitulado AVALIAÇÃO BIBLIOMÉTRICA EM INOVAÇÃO EM SERVIÇOS, tem como objetivo entender em que base foi estruturada a relação entre inovação e marketing de serviços. O marketing de serviços tem alcançado dimensões de grande relevância no mundo acadêmico e corporativo, e sua importância é impulsionada quando aliada ao construto inovação.

Perspectivas em Gestão \& Conhecimento, João Pessoa, v. 7, n. 1, p. 1-4, jan./jun. 2017. 
O décimo primeiro e último Relato de Pesquisa, intitulado COMPETÊNCIAS GERENCIAIS: UMA PERSPECTIVA DOS GESTORES DAS EMPRESAS DO AGRONEGÓCIO, de autoria de Lidiane Cássia Comin, Eliana Andréa Severo, Camila Fortuna Dall Agnol, Luciane Soares de Medeiros e Julio Cesar Ferro de Guimarães, objetiva identificar as competências gerenciais sob a percepção dos gestores em suas tomadas de decisões, através de uma pesquisa realizada com 149 gestores de empresas que atuam no setor do agronegócio, apontando para uma gestão de pessoas integrada que propicia o alinhamento entre os interesses da empresa e dos funcionários, impactando de forma positiva no desempenho da mesma.

Finalizamos agradecendo o interesse e o contributo de todos aqueles que enviaram as suas propostas de artigos, a disponibilidade e o esforço de todos os referees e equipe editorial da PG\&C, aos leitores e, de modo especial, comemorando cinco anos de sua existência, ao portal Spell. Sentimo-nos, diante disso, honrados em tornar possível mais um número da PG\&C.

João Pessoa, Paraíba, Brasil, 30 de junho de 2017.

Os Editores

Luciana Ferreira da Costa e Jorge de Oliveira Gomes

https://twitter.com/revistapgecufpb 